\title{
DISCURSOS CURRICULARES EM DISPUTA PELA SIGNIFICAÇÃO DO MUNDO: os acontecimentos e a suspensão das verdades
}

\author{
Hugo Heleno Camilo Costa \\ Universidade Federal do Mato Grosso - UFMT \\ Talita Vidal Pereira \\ Universidade Estadual do Rio de Janeiro - UERJ
}

\begin{abstract}
Éste es el límite, a la vez externo e interno, sobre el que quisiera insistir aquí: aunque la experiencia de un acontecimiento, el modo bajo el cual nos afecta, precisa de un movimiento de apropiación (comprensión, reconocimiento, identificación, descripción, determinación, interpretación a partir de un horizonte de anticipación, saber, denominación, etc.), aunque este movimiento de apropiación sea irreductible e inevitable, sólo hay acontecimiento digno de este nombre en donde esta apropiación fracasa en una de las fronteras (Derrida, 2001).
\end{abstract}

Ainda que a pandemia do Covid-19 tenha servido como um elemento provocador à chamada desse dossiê, o questionamento ao instituído, aquilo que, à primeira vista, pode parecer sedimentado e inexorável, nos mobiliza a pensar no campo do currículo. Como acontecimento, a pandemia aprofundou desigualdades, angústias, incertezas e sinalizou amplamente às ilusões que alimentamos em torno do controle. Certezas porosas sobre o que somos, o que é o outro, o que é imprescindível e/ou desejável foram expostas de forma aguda.

Como trata Derrida (2001), para ser considerado um acontecimento, é necessário que a irrupção seja de ordem imprevista, não-calculada, não-pensada, constrangedora e suceda, surpreenda e suspenda a compreensão. $\mathrm{O}$ acontecimento questiona a estruturalidade da estrutura, a segurança dos pressupostos, os limites e os termos do jogo, reprojetando-o estranhamente, demonstrando vazamentos, precariedades, descontrole.

A perspectiva do filósofo nos ajuda aqui a pensar que não há profilaxia ao imprevisto, mas os questionamentos produzidos pelo acontecimento, em uma relação com a alteridade, não deixam margem à possibilidade de não responder. Respondemos, decidimos com o que julgamos ter e como consideramos poder, frente ao desconhecido e na reunião dos sentidos que interpretamos, aqui e agora, como potencialidades para avançar em relações contingentes. 
Ao convidar o leitor à caminhada por esse dossiê, pensamos na possibilidade de conjecturar o currículo como uma subjetivação política que se constitui em resposta. Nesse caso, os trabalhos aqui reunidos podem ser tomados como rastros desse sujeito sempre porvir currículo, em busca por responder à alteridade, que também podemos chamar por pandemia.

Nos pautamos em um quadro teórico que possibilita desconfiar de nossas certezas, sem que isso signifique assumir uma postura niilista. Pelo contrário, apostamos na necessidade de realizar um investimento radical, "não apriorístico, não determinista, não essencialista" [assumindo que] "toda normatividade é decorrente de uma articulação discursiva, sem fundamento, como resposta e mobilização frente ao que se considera uma ameaça às identificações sociais (LOPES, 2015, p. 125).

Assim como a autora, também nos apropriamos das contribuições pós-fundacionais e pós-estruturais de Ernesto Laclau para defender a necessidade de investirmos radicalmente na disputa pela construção de um mundo novo. Temos nessa oportunidade interpretativa a concepção do outro como o que provoca nesse processo pensado como porvir, sem nenhuma garantia, apenas adotando uma postura responsável diante do que nos interpela.

Em algum momento, ao longo da crise provocada pelos acontecimentos que sucederam sobre nós, foi possível ainda interagir com ideias nostálgicas de que a "normalidade" poderia estar guardada em algum lugar do passado, pronta para ser acessada e revivida. As quarentenas não passaram e a espera pelo "mesmo-normal" passou a ser eclipsada por ressignificações críticas às "antigas verdades”. Nesse cenário, interagem leituras disputando a capacidade de alimentar a fantasia, a expectativa de que podemos controlar o incontrolável.

Nesse dossiê, buscamos provocar os sentidos de apego ao desejo de retomar a vida normal o mais rápido possível, mesmo sem saber como, mesmo sem a certeza da normalidade que nos espera ou a negação do quadro de destruição de tantas vidas, no Brasil e pelo mundo afora. Visamos identificar novas significações, novas possibilidades de viver reinventando a vida. É dessa perspectiva que insistimos em afirmar que a pandemia não inaugura a precariedade da vida, ela aprofunda as mazelas que a necropolítica (MBEMBE, 2018) ${ }^{1}$ já vinha produzindo ao longo dos anos.

É fato que a contaminação independe de raça, classe, gênero ou orientação sexual. No entanto, a forma de acolher o outro, os mais vulneráveis, a condição de combate ao contágio produz dinâmicas desiguais. A necropolítica se alimenta e é alimentada por essas dinâmicas. No entanto, não nos basta a sensação de obviedade que nos leva a identificar nas forças ultraconservadoras os agentes da necropolítica. Buscamos compreender os jogos de linguagem que tornam a dinâmica da necropolítica possível e nos compreendemos como parte desses jogos. Desse ponto de vista, indagamos sobre as verdades que nos enredam nesses jogos, àquilo a partir do que pensamos formas de ação, estratégias, agendas políticas. As formas como significamos a educação, a formação, o ensino também estão implicadas nessas articulações discursivas. Por isso, defendemos que nós pesquisadores em currículo 
temos o compromisso ético de produzir reflexões que possam contribuir para ampliar possibilidades e alternativas para ação nesse cenário.

Apostamos na emergência de nos engajarmos em um investimento radical pela produção de nossos significados de mundo. Muitos de nós já vêm produzindo reflexões nessa direção, mas agora, mais do que nunca, a busca por novas perspectivas se impõe como questionamento ao qual não podemos e não devemos fugir. A escola serve para quê? Qual a importância dos conhecimentos disciplinares quando defendemos dada modalidade da educação? Como aquilo que é significado como novo ameaça o trabalho docente? Que exigências a crise nos traz? Quais temas exigem de nós aprofundamento e discussão? O que está em jogo, ou em risco, quando pensamos educação nesse contexto? Estas questões ganham lugar nesse dossiê, cujo principal objetivo é construir momento de convergência de estudos que possam auxiliar na construção de um horizonte reflexivo, que compreenda as incertezas e os questionamentos que nos motivam em nossas experimentações como pesquisadores. As manifestações constituídas em artigos, pelas distintas leituras de mundo apropriadas pelas autorias aqui envolvidas, possibilitam a afirmação do campo do currículo como respondendo aos desafios que os acontecimentos envolvidos na pandemia seguem impondo.

Frente à suspensão dos tempos e espaços escolares e aos investimentos para mantê-los durante a pandemia do Covid-19, no artigo La pandemia como experiencia educacional: Algunas reflexiones sobre la escolaridad y su estudio, Daniel Johnson Mardones nos provoca a pensar esse cenário de incertezas como experiência educacional e como alegoria de processos mais permanentes nos sistemas escolares, na educação e nas sociedades em geral. O autor aposta na possibilidade de repensar a escola, o currículo e o conhecimento, restabelecendo, em um possível cenário pós-pandêmico, a questão de qual é o conhecimento mais valioso, substituído por décadas pelo desdobramento global da afirmação do saber mais importante.

Sem qualquer acordo prévio, os textos que se seguem parecem responder ao convite/chamado do autor, ampliando as possibilidades de pensar a escola e o que afirmamos como suas características, problemas e questionamentos.

No texto Aulas on-line no contexto da educação superior em tempos de pandemia, Karen Graziela Weber Machado, Felipe Sereno Soso e Adriana Justin Cerveira Kampff analisam documentos produzidos no âmbito da Associação Internacional de Universidades (IAU); da Organização das Nações Unidas para a Educação, a Ciência e a Cultura (UNESCO); do Instituto Internacional para a Educação Superior na América Latina e Caribe (IESALC); da Organização para a Cooperação e Desenvolvimento Econômico (OCDE), do Banco Mundial; do Ministério da Educação (MEC) e da Coordenação de Aperfeiçoamento de Pessoal de Nível Superior (CAPES), buscando identificar estratégias elaboradas com o objetivo de auxiliar os sistemas educacionais na execução de aulas remotas e lidar com os desafios da pandemia. Concluem que os documentos estabelecem alguns princípios para guiar a continuidade das atividades pedagógicas, dentre eles estão: o desenvolvimento de projetos pedagógicos inclusivos e equitativos, a capacitação docente 
para atuar em plataformas virtuais, e o suporte aos discentes, para engajá-los e reduzir a sensação de isolamento.

A discussão proposta por Kleiton Cassemiro e Ana Lúcia Sarmento Henrique, indaga "Para onde apontam as atuais diretrizes curriculares? Um olhar sobre as DCNs de engenharia". O texto nos remete ao questionamento sobre a seleção de conhecimentos considerados válidos para compor o currículo. A autoria faz uma reflexão tenso como objeto os cursos de engenharia e destacam que qualquer seleção traz em si uma gama de intenções que refletem o poder de quem a projeta. Nesse sentido, fazem emergir alguns questionamentos acerca dos caminhos e intenções dessa diretriz. Concluem ponderando que as DCNs para esse curso refletem um modelo de formação que tem forte influência de lógicas de mercado, o que levou a um currículo baseado em competências que visam flexibilizar a formação, tornando-a mais empreendedora e competitiva, ao mesmo tempo em que menos focada nos interesses sociais.

Gabriel Brasil de Carvalho Pedro e Márcia Serra Ferreira apresentam, no artigo intitulado Historicizando as verdades curriculares em tempos de democracia: a alquimia dos conhecimentos geográficos e a fabricação de professores e estudantes no Brasil, análise comparativa e descontínua que realizaram tomando como foco as experiências institucionalmente democráticas no país: entre o fim do Estado Novo (1946) e o Golpe Militar (1964); e a partir da Constituição de 1988. Analisando textos curriculares relativos aos Estudos Sociais e ao componente curricular Geografia na BNCC, os autores discutem as formas como as Ciências Sociais têm participado dos processos de fabricação dos sujeitos escolares.

O artigo de Lúcia Helena Alvarez Leite, Bárbara Bruna Moreira Ramalho e Paulo Felipe Lopes de Carvalho, Pandemia de COVID-19, projeto colonial e inflexões anticoloniais na educação escolar, segue em direção semelhante. A autoria toma como referência as narrativas presentes em textos jornalísticos com o objetivo de identificar a vigência do projeto colonial na educação escolar e, especialmente, as conformações por ele assumidas neste momento histórico marcado pelo distanciamento social. Mais do que fazer uma denúncia, os autores buscam explicitar alternativas anticoloniais de organização da sociedade em suas relações com a educação escolar.

Em Vivendo no mundo deles: currículo a partir de um apelo geontológico, Thiago Ranniery apresenta ensaio experimental em que aborda as práticas científicas questionando como podem insuflar transformações imaginativas nas relações entre os diferentes seres que compartilham a Terra e no que chamamos de educação. O autor interroga imbróglios coloniais que tornam o currículo equivalente a um projeto de formação do sujeito humano. Argumenta que a autocracia humanista fracassa em tirar proveito da inconstância da materialidade animada do solo ao se debater contra a perda de um terreno seguro ou estável. Ao mesmo tempo, o autor indica como controvérsias científicas testemunham um problema de comunicação quanto ao apelo geontológico de imprimir à educação o trabalho de coordenação e coexistência entre múltiplas histórias emaranhadas.

No artigo Empurrar o céu: reflexões com os cotidianos e a pandemia, Bárbara Maia Cerqueira Cazé, Mailsa Carla Pinto Passos e Juliana Ribeiro, as autoras são 
mobilizadas por sentimentos e experiências suscitadas pelas angústias e incerteza agravada em um cenário de crise sanitária. Tomando como provocação o risco a própria existência humana, refletem sobre a fundamentalidade das narrativas de diferentes grupos étnicos, historicamente alijados de direitos, como investimento para recuperar nossas utopias e reinventar caminhos.

No artigo Os vestidos da madrinha Verônica: ou como a morte aparece no currículo, Ana Angelita Rocha parte das histórias e das geografias ancestrais para problematizar a condição fronteiriça como o próprio corpo da mulher. Em particular, lança mão da concepção de mestiza, de Gloria Anzaldúa, para pensar a ideia de corpo-território como argumento curricular para questionar a ideia de fronteira cultural. Busca, nesse sentido, colocar no centro o corpo da mestiza, como condição fronteiriça para questionar a ferida colonial ainda presente nas nossas ações pedagógicas e nas nossas intenções curriculares de formação docente, sobretudo da professora.

O texto Um tempo - nem tão novo tempo - advindo da covid-19: desafios políticocurriculares no eixo Brasil-Portugal, de Ana Paula Pereira Marques de Carvalho e Elizabeth Barroso Lima, focaliza o movimento de uma crise político-educacional, em um contexto de isolamento social, que tem favorecido tentativas de ensino através do uso de plataformas virtuais. As autoras apresentam parte da pesquisa de campo, com entrevistaram a responsáveis e professores de escolas públicas e privadas das cidades do Rio de Janeiro e Lisboa, que permitem questionar a possibilidade de emoldurar o processo políticocurricular numa arte factível.

Juliano Pereira de Mello e Artur José Renda Vitorino, com o artigo Ensaio crítico sobre as possíveis estratégias adotadas para o enfrentamento ao fechamento das escolas provocado pela covid-19: rede municipal de ensino de Campinas (SP) - Brasil, nos auxiliam a compreender as formas pelas quais o projeto colonial na educação escolar se manifestam nas estratégias adotadas para o enfrentamento ao fechamento das escolas em uma rede municipal de ensino específica. $\mathrm{O}$ trabalho expressa o quão difícil é romper com as expectativas e certezas que temos sobre a escola. Tal discussão nos remete ao texto $A$ BNCC no contexto da prática: em meio a uma pandemia, é possível pensar a educação sob outras "bases"? de Joelma de Sousa Lemos e Marcia Betania de Oliveira. Investigando discursos envolvidos no contexto da prática, as autoras buscam identificar como as escolas significam/traduzem a política da BNCC dando especial atenção ao cenário de isolamento social e fechamento das escolas. Para as autoras, essa abordagem possibilita pensar a educação para além das expectativas de controle sobre o que deve ser ensinado e aprendido.

O fechamento das escolas no contexto Iberoamericano também é tema do artigo COVID-19 y el cierre de escuelas: aportes de las ciencias sociales para la construcción de un currículo postcrítico desde el Geoforo Iberoamericano, de Silvia Aparecida de Sousa Fernandes, Diego García Monteagudo e Nancy Palacios Mena. A autoria discute as concepções de professores e alunos de três países ibero-americanos (Brasil, Colômbia e Espanha) e destaca experiências e determinações escolares frente à pandemia COVID-19, por meio da análise do $26^{\circ}$ Fórum Ibero-americano sobre Educação, Geografia e Sociedade (GEOFORO). Desenvolvem o argumento de que os desafios enfrentados pelos professores 
da educação básica frente as demandas por educação a distância são maiores no contexto de pandemia, uma vez que situações de isolamento social e quarentena apresentam novos desafios para projetos de educação em ciências sociais voltados a uma cidadania crítica.

A Educação Infantil e a Educação de Jovens e Adultos são pensadas nesse conjunto de reflexões com Alessandra Nicodemos e Enio Serra, que discutem no texto Educação de jovens e adultos em contexto pandêmico: entre o remoto e a invisibilidade nas políticas curriculares os efeitos da crise sanitária na vida dos trabalhadores que cursam a Educação Básica. Destacam as repercussões nas políticas curriculares dirigidas a essa modalidade de ensino e concluem com um alerta sobre a complexidade e gravidade da atual conjuntura ao pensarem possíveis ameaças à EJA, em seu projeto de garantia do direito à educação socialmente referenciada para jovens, adultos e idosos das classes populares.

Por sua vez, a Educação Infantil ganha centralidade no texto de Raul Cabral França, Marina Basques Masella e Ana Maria Falcão de Aragão, intitulado A educação infantil na pandemia: a experiência de uma escola pública antirracista. $\mathrm{O}$ artigo apresenta parte da pesquisa desenvolvida sobre o projeto político-pedagógico de uma escola municipal de educação infantil, que adota as relações étnico-raciais como um de seus eixos principais. Destaca as estratégias desenvolvidas pela instituição durante a suspensão do atendimento presencial, em razão da pandemia de COVID-19. Analisa as possibilidades e os limites para efetivar, nesse contexto, um currículo antirracista, centrado na ludicidade e na afetividade; discute, também, os desafios para a inclusão de todas as crianças no processo e para a garantia do direito à educação.

Por fim, Júlio César Augusto do Valle discute os posicionamentos da Associação Nacional de Pós-graduação e Pesquisa em Educação (ANPEd) e da Associação Brasileira de Currículo (AbdC), no artigo As Associações científicas da educação e a Base Nacional Comum Curricular (BNCC) no contexto do sequestro da democracia brasileira durante o processo de discussão/elaboração da BNCC. O autor desenvolve uma análise documental dando destaque aos ofícios e notas elaborados pelas associações científicas. Salienta as tensões envolvidas nas negociações, demonstrando a busca das associações por representação no diálogo com as instâncias governamentais. Aponta para as dificuldades que marcam essa interlocução com o governo e para a responsabilidade pública com a educação que tais associações incorporam.

\section{Nota}

1. Trata-se do questionamento se o Estado possui ou não "licença pra matar" em prol de um discurso de ordem que aqui ampliamos para pensar em ações do Estado que privilegiam a ordem econômica em detrimento da proteção à vida das pessoas.

\section{Referências}


DERRIDA, Jacques. La filosofía en una época de terror. Diálogos con Jürgen Habermas y Jacques Derrida. Taurus: Buenos Aires, 2004.

LOPES, Alice C. Normatividade e intervenção política: em defesa de um investimento radical. In: LOPES, Alice C; MENDONÇA, Daniel de (Org.). A teoria do discurso de Ernesto Laclau. Ensaios críticos e entrevistas. São Paulo: Annablume, 2015, pp. 117- 147.

MBEMBE, Achille. Necropolítica. 3. ed. São Paulo: N-1 edições, 2018.

\section{Correspondência}

Hugo Heleno Camilo Costa: Doutor em Educação pelo Programa de Pós-Graduação em Educação (ProPEd) da UERJ. Professor do Instituto de Ciências Humanas e Sociais da Universidade Federal de Mato Grosso (ICHS/UFMT Araguaia) e do Programa de Pós-Graduação em Educação (PPGEdu) da Universidade Federal de Rondonópolis. É coordenador do Núcleo de Estudos em Currículo, Cultura e Subjetividades (NECSUS). Atualmente é vice-coordenador do GT Currículo da Associação Nacional de Pós-Graduação e Pesquisa em Educação (2019-2021), membro da Câmara de Pós-graduação e Pesquisa da UFMT. Seu foco investigativo está nas políticas envolvidas no debate sobre conhecimento, subjetividades e currículo.

E-mail: hugoguimel@gmail.com

Talita Vidal Pereira: Professora Associada na Universidade do Estado do Rio de Janeiro. Professora permanente do Programa de Pós-Graduação em Educação e do Programa de Pós-Graduação em Educação, Cultura e Comunicação, ambos da UERJ. Bolsista Produtividade Nível 2 do CNPq, bolsista do Programa Jovem Cientista da FAPERJ e do Programa Prociência da UERJ/FAPERJ. Líder do Grupo de Pesquisa Conhecimento, Currículo e Avaliação. Áreas de interesse: Currículo e Avaliação; Conhecimento Escolar; Formação Docente.

E-mail: p.talitavidal@gmail.com

Texto publicado em Currículo sem Fronteiras com autorização dos autores 